\title{
Teor e composição do óleo essencial de inflorescências e folhas de Lavandula dentata L. em diferentes estádios de desenvolvimento floral e épocas de colheita
}

\author{
MASETTO, M.A.M. ${ }^{1 *}$; DESCHAMPS, C. ${ }^{1}$; MÓGOR, A.F. ${ }^{1}$ BIZZO, H.R. ${ }^{2}$ \\ ${ }^{1}$ Departamento de Fitotecnia e Fitossanitarismo- Produção Vegetal, Universidade Federal do Paraná, Caixa Postal \\ 19061, CEP: 81531-990, Curitiba-Brasil ²Embrapa Agroindústria de Alimentos, Avenida das Américas, 29501, \\ CEP:23020-470, Rio de Janeiro-Brasil*magdamasetto@pop.com.br; cícero@ufpr.br
}

\begin{abstract}
RESUMO: O óleo essencial de Lavandula dentata L. possui importância econômica devido à utilização nas indústrias farmacêutica, cosmética e de higiene pessoal. O presente trabalho teve como objetivo avaliar o teor e a composição do óleo essencial de inflorescências e folhas de lavanda em diferentes estádios de desenvolvimento. O delineamento experimental foi inteiramente casualizado em esquema fatorial $2 \times 3$, sendo três estádios de desenvolvimento floral (botão, pré-antese/antese e senescente) e duas épocas de colheita (janeiro e abril), com cinco repetições. As amostras de óleo essencial foram obtidas por hidrodestilação, sendo os constituintes analisados por cromatografia em fase gasosa acoplada à espectrometria de massas (CG/EM). Houve interação entre os fatores épocas de colheita e desenvolvimento floral no teor de óleo essencial das inflorescências, sendo observada média superior em botões florais colhidos em janeiro. Os estádios de desenvolvimento não alteraram o teor do óleo essencial das folhas. Os estádios de desenvolvimento influenciaram nos teores dos constituintes dos óleos essenciais das inflorescências e folhas. No óleo essencial em estádio de flor senescente da colheita de abril, observou-se teor elevado de 1,8-cineol, enquanto nos demais estádios de desenvolvimento os teores foram menores em ambas as épocas de colheita. Teores elevados de cânfora foram observados nos estádios de pré-antese/antese e senescente, na colheita de janeiro. $O$ óleo essencial das folhas apresentou teor superior de 1,8-cineol em ramos com flores em estádio de pré-antese/antese. Os teores de cânfora e fenchona foram superiores em ramos contendo botões. $O$ óleo essencial das folhas de ramos com botões e flores senescentes apresentou teor superior de linalol em relação ao óleo essencial das inflorescências.
\end{abstract}

Palavras-chave: lavanda, planta aromática, 1,8-cineol, cânfora, linalol

\begin{abstract}
Yield and composition of essential oil from inflorescences and leaves of lavender (Lavandula dentata L.) in different flower development stages and harvest times. The essential oil of Lavandula dentata $L$. has economic importance due to its utilization by pharmaceutical, cosmetic and personal care industries. The aim of this study was to evaluate the yield and composition of essential oil from lavender inflorescences and leaves in different development stages. The experimental design was completely randomized in $2 \times 3$ factorial arrangement, with three flower development stages (bud, pre-anthesis/anthesis and senescence) and two harvest periods (January and April), and 5 replicates. The essential oil samples were obtained by hydrodistillation, and the compounds were analyzed by gas chromatography coupled to mass spectrometry (GC/MS). There was an interaction between the factors harvest time and flower development on essential oil yield of inflorescences, and a superior average was observed for flower buds harvested in January. The development stages did not alter the essential oil yield of leaves. The development stages influenced the levels of compounds of the essential oil from inflorescences and leaves. For essential oil in senescent flower stage harvested in April, there was a high level of 1,8-cineol, whereas in the remaining development stages, the levels were lower in both harvest times. The levels of camphor increased in the pre-anthesis/anthesis and senescence in January harvest. The essential oil from leaves presented higher levels of 1,8-cineol in branches with flowers in pre-anthesis/anthesis. Camphor and fenchone levels were higher in branches with buds. The essential oil from leaves of branches with buds and senescent flowers showed higher levels of linalool than that from inflorescences.
\end{abstract}

Key words: lavender, aromatic plants, 1,8-cineol, camphor, linalool

Recebido para publicação em 28/09/2009

Aceito para publicação em 21/04/2011

Rev. Bras. PI. Med., Botucatu, v.13, n.4, p.413-421, 2011. 


\section{INTRODUÇÃO}

Entre os gêneros aromáticos da família Lamiaceae mais conhecidos, encontra-se o gênero Lavandula que possui destaque na economia mundial devido à produção de óleos essenciais utilizados nas indústrias de perfumaria, cosmética (Bombarda et al., 2008), alimentos (Da Porto et al., 2009) e terapêutica (Cassella et al., 2002).

Os principais compostos do óleo essencial de Lavandula dentata L. são os monoterpenos oxigenados $(68,6 \%)$, seguido dos monoterpenos hidrocarbonados $(2,7 \%)$, sesquiterpenos oxigenados $(2,6 \%)$ e sesquiterpenos hidrocarbonados (2,6\%) (Dob et al., 2005). A presença dos monoterpenos oxigenados 1,8-cineol e cânfora conferem ao óleo essencial propriedades medicinais e terapêuticas com ações antiespasmódica, antifúngica e bactericida (Chu \& Kemper, 2001; Moon et al., 2006), antiinflamatórias e analgésicas (Hajhashemi et al., 2003), atuando ainda como repelente e inseticida (Yusufoğlu et al., 2004).

Estes compostos encontram-se armazenados em tricomas glandulares peltados distribuídos por toda a parte aérea da planta (Sudriá et al., 1999). Segundo Muñoz-Bertomeu et al. (2007), o órgão onde os tricomas glandulares se distribuem (flores ou folhas) afeta o teor do óleo essencial de L. latifolia Medikus, sendo as flores o órgão com maior capacidade de acúmulo. Em L. dentata, cultivada na região da Argélia, o teor de óleo essencial de folhas e ramos por sua vez foi $83,7 \%$ superior ao obtido de flores (Bousmaha et al., 2005).

A produtividade e a variabilidade fitoquímica do óleo essencial em espécies aromáticas estão relacionadas à fase de desenvolvimento, idade da planta, órgão de armazenamento (Sangwan et al., 2001) e às condições ambientais as quais as plantas estão submetidas (Gobbo-Neto \& Lopes, 2007).

A composição do óleo essencial das flores e folhas de $L$. coronopofolia Poiert. apresentou variações pequenas nos teores dos constituintes linalol $(41,1 \%$ e $40,8 \%)$, cânfora ( $11,6 \%$ e $12,1 \%)$, 1,8 -cineol $(7,3 \%$ e $7,7 \%)$ respectivamente, enquanto que os teores destes constituintes no óleo essencial obtido de toda a parte aérea da planta (flores, folhas e ramos) foram menores (linalol 20,8\%; cânfora 19,7\% e 1,8-cineol 25,4\%) (Aburjai et al., 2005). Em L. dentata, a composição do óleo essencial de toda parte aérea comparado ao apenas de folhas e ramos apresentou teores superiores de 1,8-cineol $(36,4 \%)$, $\beta$-pineno ( $8,1 \%)$, limoneno $(3,9 \%)$, enquanto que a composição do óleo extraído apenas de flores, apresentou baixos teores destes constituintes, $(1,8$ cineol $21,5 \%$, $\beta$-pineno $6,0 \%$ e limoneno $2,5 \%$ ) (Bousmaha et al., 2005). Os autores verificaram ainda que, além do estádio de desenvolvimento, a época de colheita afetou o teor e composição do óleo essencial sendo o maior teor obtido da parte aérea sem flores $(1,1 \%)$ colhida no penúltimo mês do florescimento e menor na parte aérea com flores $(0,6 \%)$ colhida no último mês. Maiores teores de $\beta$ pineno $(22,2 \%)$, 1,8-cineol $(3,3 \%)$, e linalol $(3,1 \%)$, foram observados nos últimos meses do florescimento.

A espécie $L$. dentada apresenta bom desenvolvimento nas condições brasileiras e a avaliação de fatores relacionados à sua produção de óleo essencial pode contribuir para a adoção de práticas adequadas de cultivo. Neste trabalho, objetivou-se determinar o teor e a composição do óleo essencial extraído de inflorescências e folhas de $L$. dentata L. em diferentes estádios de desenvolvimento floral e épocas de colheita.

\section{MATERIAL E MÉTODO}

\section{Material vegetal e cultivo}

A produção de mudas foi conduzida em casa de vegetação, do Setor de Ciências Agrárias da Universidade Federal do Paraná (UFPR), PR. O material vegetal utilizado neste experimento foi obtido de matrizes procedentes da região Metropolitana de Curitiba, PR. As exsicatas do material encontram-se depositadas no Herbário do Departamento de Botânica do Setor de Biológicas da Universidade Federal do Paraná, Curitiba, PR, sob o registro no UPCB 61305, e no Herbário das Faculdades Integradas Espírita (HFE), Curitiba, PR, sob o registro № 7207.

As mudas foram produzidas em agosto de 2006, sendo obtidas por meio de estaquias utilizandose ramos com 5 a $10 \mathrm{~cm}$ de comprimento e 2 a 3 pares de folhas na região apical. As estacas foram mantidas em substrato Plantmax $\mathrm{HT}^{\circledR}$ durante 60 dias, e sob irrigação intermitente com três turnos de irrigação, sendo de 15 segundos a cada 15 minutos das 8 às 17 horas, 15 segundos a cada hora das 17 às 23 horas e 15 segundos a cada 3 horas das 23 às 8 horas.

Após este período as mudas que apresentaram desenvolvimento vegetativo satisfatório, e boas condições fitossanitárias foram transplantadas em sacos plásticos contendo $50 \%$ de Plantmax $\mathrm{HT}^{\circledR}$ e $50 \%$ de solo. As mudas permaneceram em condições de casa de vegetação com irrigação manual durante 150 dias, sendo transplantadas para o campo em fevereiro de 2007.

O experimento foi conduzido no Centro de Estações Experimentais do Canguiri da Universidade Federal do Paraná, no município de Pinhais - PR, (251'S; 4414'W; $950 \mathrm{~m}$ de altitude). A região apresenta clima subtropical úmido meso-térmico (Silva et al., 2003). A análise do solo foi realizada coletando amostras da área experimental na profundidade de 0 a $20 \mathrm{~cm}$, e apresentou $\mathrm{pH} S M P=$ 
6,$5 ; \mathrm{Al}^{+3}=0,0 \mathrm{cmol}_{\mathrm{c}} \mathrm{dm}^{-3} ; \mathrm{H}^{++} \mathrm{Al}^{+3}=3,4 \mathrm{cmol}_{\mathrm{cm}} \mathrm{dm}^{-3}$ $\mathrm{Ca}^{+2}=9,6 \mathrm{cmol} \mathrm{dm}^{-3} ; \mathrm{Mg}^{+2}=4,2 \mathrm{cmol}^{-3} ; \mathrm{K}^{+}=1,5$ $\mathrm{cmol}_{\mathrm{c}} \mathrm{dm}^{-3} ; \mathrm{P}=274,0 \mathrm{mg} \mathrm{dm}^{-3} ; \mathrm{C}=31,7 \mathrm{mg} \mathrm{dm}^{-3}$; saturação de bases $=82,0 \%$ e teor de argila de 425 $\mathrm{g} \mathrm{kg}^{-1}$. A correção da fertilidade e acidez da área foi realizada segundo recomendação de adubação e calagem da Comissão de Química e Fertilidade do Solo de RS e SC (SBCS, 2004) para Mentha spp, sendo incorporados $10 \mathrm{~kg} \mathrm{ha}^{-1}$ de $\mathrm{N}$ na forma de uréia, $40 \mathrm{~kg} \mathrm{ha}^{-1}$ de $\mathrm{P}_{2} \mathrm{O}_{5}$ na forma de super fosfato triplo, 30 $\mathrm{kg} \mathrm{ha}^{-1}$ de $\mathrm{K}_{2} \mathrm{O}$ na forma de cloreto de potássio e 1,4 t ha-1 de calcário tipo Filler (PRNT 100\%). A adubação de cobertura foi realizada com $10 \mathrm{~kg} \mathrm{ha}^{-1}$ de $\mathrm{N}$ aos 30 dias após o plantio.

\section{Colheita e extração}

As colheitas foram realizadas em janeiro e abril de 2008, onde as condições ambientais no decorrer das épocas de colheitas são apresentadas na Figura 1.

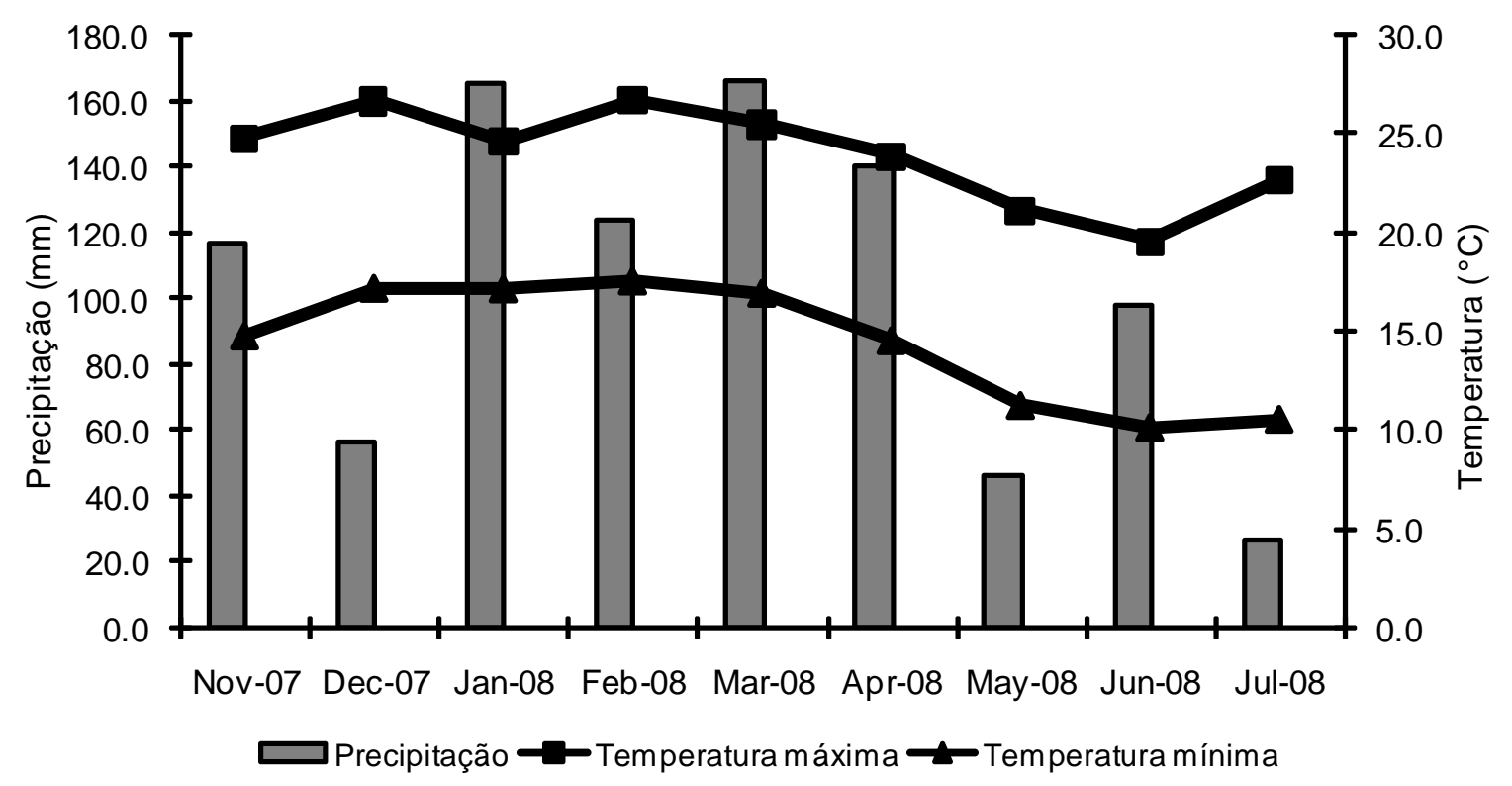

FIGURA 1. Médias mensais de temperaturas máximas e mínimas, precipitação, da área experimental. Fonte: Instituto Tecnológico Simepar (2008).

O delineamento experimental foi inteiramente casualizado em esquema fatorial $2 \times 3$, sendo dois períodos de colheita (janeiro e abril) e três estádios de desenvolvimento das inflorescências (botão, préantese/antese e senescente), com cinco repetições, cada qual com 80 gramas de inflorescências coletadas aleatoriamente de plantas adultas.

As inflorescências foram classificadas de acordo com o desenvolvimento, sendo consideradas em estádio de botão aquelas com 2 a $3 \mathrm{~cm}$ de comprimento (Figuras 2A e 2B); em pré-antese/antese com 3 a $5 \mathrm{~cm}$ (Figuras 2C e 2D) e senescente acima de $5 \mathrm{~cm}$ (Figuras 2E e 2F).

A extração do óleo essencial foi realizada por hidrodestilação durante $2 \mathrm{~h}$ em aparelho graduado tipo Clevenger com balão volumétrico com capacidade de $2 \mathrm{~L}$, utilizando-se $30 \mathrm{~g}$ de inflorescências. $\mathrm{Na}$ colheita de abril foram coletadas $30 \mathrm{~g}$ amostras de folhas de ramos com inflorescências em cada estádio de desenvolvimento (botão, pré-antese/antese e senescente) para a extração de óleo essencial.

O teor de óleo essencial foi determinado com o auxílio de micropipetas de precisão (0-100 $\mu \mathrm{L})$, sendo as amostras mantidas congeladas à -18ㄷ até o momento da análise. A análise dos constituintes do óleo essencial das inflorescências e folhas de $L$. dentata, foi realizada por cromatografia em fase

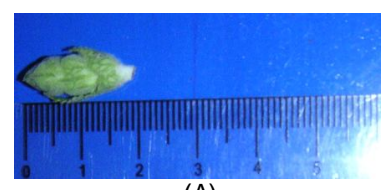

(A)

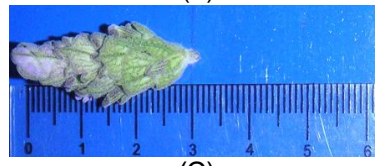

(C)

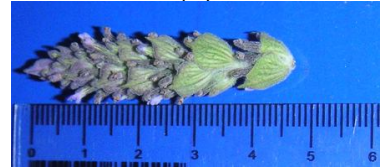

$(\mathrm{E})$

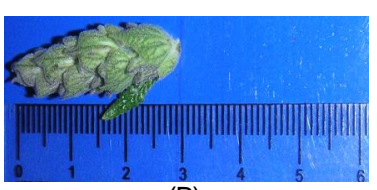

(B)

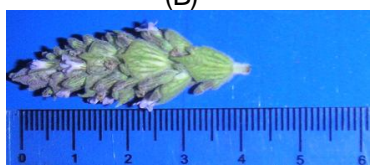

(D)

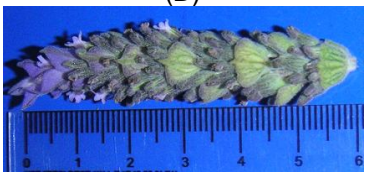

$(\mathrm{F})$
FIGURA 2. Estádios de desenvolvimento das inflorescências de L. dentata L. (A e B) botão, (C e D) pré-antese/antese e (E e F) senescente. 
gasosa, em equipamento Agilent $6890 \mathrm{~N}$, com detector de ionização por chama (DIC), operado a $280^{\circ} \mathrm{C}$ e uma coluna HP5 (30 m X 0,32 mm X 0,25 $\mu \mathrm{m})$, utilizando-se hidrogênio como gás de arraste $\left(1,5 \mathrm{~mL} \mathrm{~min}^{-1}\right)$. Foi injetado $1,0 \mu \mathrm{L}$ de uma solução a $1 \%$ da amostra em diclorometano em injetor aquecido a 250ํㅡㄹ operando no modo com divisão de fluxo (1:20). A programação de temperatura do forno foi de $60^{\circ} \mathrm{C}$ a $240^{\circ} \mathrm{C}$, a uma taxa de aquecimento de $3^{\circ} \mathrm{C} \mathrm{min}^{-1}$. Para a quantificação, foram utilizados os valores de área normalizada, expressos em porcentagem.

Os espectros de massas foram obtidos em cromatógrafo Agilent $6890 \mathrm{~N}$ acoplado ao detector seletivo de massas Agilent 5973N, equipado com coluna capilar HP5MS (30 m X0,32 mm X0,25 $\mu \mathrm{m})$ utilizando hélio como gás carreador $\left(1,0 \mathrm{~mL} \mathrm{~min}^{-1}\right)$, nas mesmas condições utilizadas acima. $O$ detector foi operado no modo impacto eletrônico, com energia de ionização de $70 \mathrm{eV}$. Os índices de retenção para o óleo essencial das inflorescências e folhas foram calculados após a injeção de uma série homóloga de $n$-alcanos, nas mesmas condições utilizadas para as amostras. A identificação dos constituintes do óleo foi realizada por comparação dos índices de retenção calculados com os valores da literatura (Adams, 2001) e pela comparação dos espectros de massas obtidos com aqueles da biblioteca Wiley 6th ed (275.000).

As análises de variância foram realizadas utilizando-se o programa estatístico ASSISTAT versão 7.4 beta (Silva \& Azevedo, 2006). As variâncias dos tratamentos foram testadas quanto à homogeneidade pelo teste de Bartlett e as médias dos tratamentos comparadas pelo teste de Tukey a $5 \%$ de probabilidade.

\section{RESULTADO E DISCUSSÃO}

Teor de óleo essencial das inflorescências Houve interação entre os fatores época de colheita e desenvolvimento das inflorescências no teor do óleo essencial de L. dentata, sendo este significativamente superior em estádio de botão nas colheitas realizadas em janeiro e abril (Tabela 1). Além disso, na colheita de janeiro o teor de óleo essencial das inflorescências em estádio de botão apresentou 20,36 $\mu \mathrm{L} \mathrm{g}^{-1}$ de massa seca, e na colheita de abril reduziu para 17,61 $\mu \mathrm{L} \mathrm{g}^{-1}$ de massa seca. Quando a colheita foi realizada em janeiro, o teor de óleo essencial das inflorescências em estádio senescente foi $(85,0 \%)$ menor em relação à colheita de abril. As inflorescências em estádio de pré-antese/antese e senescente colhidas em abril não apresentaram diferenças nos teores de óleo essencial.

Os teores superiores de óleo essencial observados em botões de $L$. dentata podem estar relacionados à proteção dos tricomas glandulares peltados pelo cálice floral, uma vez que o cálice recobre todas as estruturas florais neste estádio (Werker, 2000). Em lavandin (L. angustifolia x L. latifolia), os tricomas glandulares peltados estão localizados na superfície externa das flores (Chávez, 2007), e nas flores de $L$. officinalis os tricomas glandulares estão na superfície interna e externa da corola Werker (2000). A ontogenia da estrutura floral também pode contribuir para o maior acúmulo em botões.

As características genéticas das espécies aromáticas também podem alterar o acúmulo do óleo essencial. Em menta (Gershenzon et al., 2000) e manjericão (Deschamps et al., 2006) têm sido observado maior teor de óleo essencial em tecidos jovens decorrentes da maior expressão de genes envolvidos com a síntese de constituintes de óleos essenciais. Avaliações anteriores, em outras espécies do gênero Lavandula, demonstram também efeito do fator genético. Resultados semelhantes foram obtidos por Beus (2006) em L. angustifolia onde teores superiores ocorreram em botão e em préantese/antese. Por outro lado, em lavandin ( $L$. angustifolia $\times$ L. latifolia), o teor de óleo essencial das inflorescências nos estádios de antese e senescente são $18,0 \%$ e 16,0\% respectivamente, superiores ao teor de óleo essencial das inflorescências no estádio de pré-antese (Kaloustian

TABELA 1. Teor ( $\mu \mathrm{L} \mathrm{g}^{-1}$ massa seca) de óleo essencial das inflorescências de $L$. dentata em estádios de desenvolvimento floral e épocas de colheita, 2008.

\begin{tabular}{cccc}
\hline \multirow{2}{*}{ Colheita } & \multicolumn{3}{c}{ Estádios de desenvolvimento } \\
\cline { 2 - 4 } & Botão & Pré-antese/antese & Senescente \\
\hline Janeiro & $20,36 \mathrm{Aa}$ & $6,29 \mathrm{Ba}$ & $0,68 \mathrm{Cb}$ \\
Abril & $17,61 \mathrm{Ab}$ & $6,35 \mathrm{Ba}$ & $4,52 \mathrm{Ba}$ \\
\hline C.V. (\%) & 20,76 & & \\
\hline
\end{tabular}

Médias com mesmas letras maiúsculas nas linhas e minúsculas nas colunas não diferem estatisticamente pelo Teste de Tukey a 5\% de probabilidade.

Rev. Bras. Pl. Med., Botucatu, v.13, n.4, p.413-421, 2011. 
et al., 2000). Em L. x intermedia cv. Grosso o teor de óleo essencial aumentou $62,5 \%$ com 0 desenvolvimento floral, onde o maior acúmulo ocorreu quando as inflorescências apresentavam desenvolvimento em $30 \%$ de antese $(32,5 \%)$, após este período o teor de óleo reduziu $27,7 \%$ até o estádio senescente, enquanto nas inflorescências de L. angustifolia cv. Munstead a variação no teor de óleo essencial foi menor (14,3\%) durante os estádios de desenvolvimento, reduzindo $14,0 \%$ até o estado senescente (Boeckelmann, 2008).

Com relação às épocas de colheita, em janeiro observou-se temperatura e precipitação, superiores ao período de abril (Figura 1), o que contribuiu para menor acúmulo de óleo essencial das inflorescências em estádio senescente. Segundo Sangwan et al. (2001) e Gershenzon et al. (2000), fatores ambientais podem alterar o teor de óleo essencial, onde dias longos de sol favorecem o florescimento, porém períodos de chuva durante o florescimento reduzem o acúmulo de óleo essencial.

\section{Composição do óleo essencial das inflorescências}

Os constituintes majoritários identificados no óleo essencial das inflorescências de $L$. dentata em estádios de desenvolvimento de botão, pré-antese/ antese e senescente, foram os monoterpenos hidrocarbonados ( $\alpha$-pineno, $\beta$-pineno e limoneno) e os monoterpenos oxigenados (1,8-cineol, fenchona, linalol, $\alpha$-fenchol e cânfora). A composição do óleo essencial foi afetada pelo estádio de desenvolvimento floral, sendo observados teores superiores de $\beta$-pineno
(5,2\% e 5,3\%), $\alpha$-pineno (2,8\% e 2,4\%), limoneno $(3,1 \%$ e $4,4 \%)$ e linalol $(2,6 \%$ e $3,2 \%)$ nas inflorescências em estádios de botão nas colheitas de janeiro e abril, respectivamente. Com o desenvolvimento das inflorescências em estádio de pré-antese/antese e senescente os teores destes mesmos constituintes reduziram em $63 \%$ e $51 \% \beta$ pineno, $73 \%$ e $54 \%$ a-pineno, $48 \%$ e $47 \%$ limoneno e $11 \%$ e $21 \%$ linalol, nas colheitas de janeiro e abril respectivamente (Tabela 2).

Os teores dos constituintes fenchona e cânfora apresentaram por sua vez, teores inferiores nas inflorescências em estádio de botão $(10,4 \%$ e $16,3 \%)$ e senescente $(11,7 \%$ e $12,9 \%)$ nas colheitas de janeiro e abril respectivamente. De forma contrária, o teor de cânfora em flores de $L$. x intermedia foi superior $43,4 \%$ em estádio de botão, quando comparado ao teor nas inflorescências em estado senescente (Boeckelmann, 2008). O teor de 1,8-cineol foi inferior (17,9\% e $21,9 \%$ ) no óleo essencial das inflorescências em estádio de pré-antese/antese em ambas as colheitas respectivamente, enquanto inflorescências em estádio de botão do mesmo constituinte não apresentaram variações na época de colheita (23,9\% e 23,7\%), e em estádio senescente aumentou de $20,7 \%$ na colheita de janeiro para $27, \%$ na colheita de abril.

A composição do óleo essencial de $L$. dentata cultivada na Argélia durante o desenvolvimento floral apresentou no início do florescimento $(4,2 \% \alpha-$ pineno, 0,9\% 1,8-cineol, 14,4\% $\beta$-pineno e 0,4\% cânfora) na antese (7,7\% $\alpha$-pineno, 3,9\% 1,8-cineol, $25,5 \% \beta$-pineno e $0,5 \%$ cânfora) no final do

TABELA2. Constituintes (\%) do óleo essencial das inflorescências de L. dentata, em estádios de desenvolvimento floral e épocas de colheita, 2008.

\begin{tabular}{|c|c|c|c|c|c|c|}
\hline \multirow{4}{*}{ Constituintes } & \multicolumn{6}{|c|}{ Época de colheita } \\
\hline & \multicolumn{3}{|c|}{ Janeiro } & \multicolumn{3}{|c|}{ Abril } \\
\hline & \multicolumn{6}{|c|}{ Estádios de Desenvolvimento } \\
\hline & Botão & $\begin{array}{c}\text { Pré- } \\
\text { antese/antese }\end{array}$ & Senescente & Botão & $\begin{array}{c}\text { Pré- } \\
\text { antese/antese }\end{array}$ & Senescente \\
\hline 1,8 Cineol & 23,9 & 17,9 & 20,7 & 23,7 & 21,9 & 27,0 \\
\hline Cânfora & 16,3 & 23,5 & 23,2 & 15,1 & 19,7 & 20,9 \\
\hline Fenchona & 10,4 & 13,2 & 11,7 & 11,0 & 12,3 & 12,9 \\
\hline a-Fenchol & 5,5 & 7,1 & 5,9 & 5,6 & 6,3 & 5,8 \\
\hline$\beta$-Pineno & 5,2 & 1,9 & 1,9 & 5,3 & 2,3 & 2,9 \\
\hline Limoneno & 3,1 & 1,7 & 1,5 & 4,4 & 2,5 & 2,1 \\
\hline a-Pineno & 2,8 & 0,7 & 0,8 & 2,4 & 0,7 & 1,4 \\
\hline Linalol & 2,6 & 1,7 & 1,0 & 3,2 & 2,9 & 1,8 \\
\hline \% Total Identificados & 69,8 & 67,7 & 66,6 & 70,7 & 68,5 & 74,8 \\
\hline Demais Constituintes & 30,2 & 32,3 & 33,4 & 29,3 & 31,5 & 25,2 \\
\hline \% Total & 100,0 & 100,0 & 100,0 & 100,0 & 100,0 & 100,0 \\
\hline
\end{tabular}


florescimento (4,8\% $\alpha$-pineno, 1,5\% 1,8-cineol, $16 \%$ $\beta$-pineno e 0,9\% cânfora) (Bousmaha et al., 2005).

Estas alterações nos teores dos constituintes do óleo essencial também podem estar relacionadas com reações químicas reguladas pelo nível de expressão gênica e/ou atividade de enzimas regulatórias da síntese dos constituintes do óleo essencial (Gershenzon et al., 2000). Em flores de boca de leão (Antirrhinum majus L.), a emissão do composto volátil metil benzoato foi superior quatro dias após a antese e reduziu gradualmente após este período (Dudareva et al., 2000). Segundo os autores, a emissão do metil benzoato é regulada pelo nível do substrato ácido benzóico e pela atividade da enzima ácido benzóico metil transferase.

Os teores dos constituintes observados neste trabalho diferem de relatos anteriores sobre a composição do óleo essencial das flores de $L$. dentata, principalmente com relação ao constituinte cânfora. Conforme Bousmaha et al. (2005), os constituintes cânfora e fenchona não foram identificados no óleo essencial de flores de $L$. dentata. Boeckelmann (2008), concluiu que o acúmulo de monoterpenos em L.x intermedia e $L$. angustifolia cv. Munstead, são específicos da espécie, podem variar conforme a condições climáticas, como também são reguladas pelo desenvolvimento e pelo nível de expressão gênica.

\section{Teor de óleo essencial das folhas e inflorescências}

Houve interação significativa para o teor de óleo essencial nos órgãos de armazenamento e estádios de desenvolvimento para a colheita de abril. O teor de óleo essencial das inflorescências foi superior nas inflorescências em estádio de botão (17,61 $\mu \mathrm{L} \mathrm{g}^{-1}$ massa seca) com o desenvolvimento das inflorescências os teores de óleo essencial reduziram para $6,35 \mu \mathrm{L} \mathrm{g}^{-1}$ massa seca em estádio pré-antese/antese e $4,52 \mu \mathrm{L} \mathrm{g}^{-1}$ massa seca em senescente. Enquanto nas folhas não houve diferença estatística dos teores em relação aos estádios de desenvolvimento floral. Considerando o órgão de armazenamento, as folhas de $L$. dentata apresentaram teores superiores de óleo essencial, sem diferença estatística em estádio de botão $\left(19,20 \mu \mathrm{L} \mathrm{g}^{-1}\right.$ massa seca) e estatisticamente diferente em estádio de préantese/antese (21,30 $\mu \mathrm{L} \mathrm{g}^{-1}$ massa seca) e senescente $\left(18,27 \mu \mathrm{L} \mathrm{g}^{-1}\right.$ massa seca) (Tabela 3).

TABELA 3. Teor ( $\mu \mathrm{Lg}^{-1}$ massa seca) de óleo essencial das inflorescências e folhas de $L$. dentata em estádios de desenvolvimento floral, 2008.

\begin{tabular}{cccc}
\hline \multirow{2}{*}{ Local de armazenamento } & \multicolumn{3}{c}{ Estádio de desenvolvimento } \\
\cline { 2 - 4 } & Botão & Pré-antese/antese & Senescente \\
\hline Inflorescências & $17,61 \mathrm{Aa}$ & $6,35 \mathrm{Bb}$ & $4,52 \mathrm{Bb}$ \\
Folhas & $19,20 \mathrm{Aa}$ & $21,30 \mathrm{Aa}$ & $18,27 \mathrm{Aa}$ \\
\hline C.V. (\%) & 19,68 & & \\
\hline
\end{tabular}

Médias com mesmas letras maiúsculas nas linhas e minúsculas nas colunas não diferem estatisticamente pelo Teste de Tukey a 5\% de probabilidade.

Estudos do estádio de desenvolvimento da planta associado ao teor de óleo essencial das inflorescências e folhas com outras espécies do gênero Lavandula apresentaram resultados contrários ao encontrado neste estudo. O teor de óleo essencial das folhas de lavandin (L. angustifolia $\times$ L. latifolia) foram inferiores ao teor de óleo essencial das inflorescências em estádios de pré-antese (93\%), antese (95\%) e senescente (100\%), (Kaloustian et al., 2000). Também em L. x intermedia, o teor de óleo das folhas nos estádios de desenvolvimento foi inferior ao teor de óleo essencial das inflorescências (Boeckelmann, 2008). Bousmaha et al. (2005) observaram teor de óleo essencial crescente $(0,5 \%$ pré-antese à $1,1 \%$ antese) durante o período do florescimento em folhas e ramos de $L$. dentata, com redução no final do florescimento para $0,6 \%$.
De acordo com Boeckelmann (2008), o acúmulo de óleo essencial nas inflorescências de $L$. $\mathrm{x}$ intermedia aumentou (12 à $33 \mathrm{mg} \mathrm{g}^{-1}$ massa seca ) com o desenvolvimento floral até $30 \%$ após antese, reduzindo até estádio senescente (33 à $24 \mathrm{mg} \mathrm{g}^{-1}$ massa seca), enquanto, nas folhas das mesmas espécies o acúmulo de óleo diminuiu (5,5 - 1,3 $\mathrm{mg} \mathrm{g}^{-1}$ massa seca) com a maturidade dos tecidos, em $L$. angustifólia o teor de óleo manteve-se estável (15 mg $\mathrm{g}^{-1}$ massa seca) durante o desenvolvimento floral, e nas folhas também reduziu $\left(2,9-0,7 \mathrm{mg} \mathrm{g}^{-1}\right.$ massa seca) com a maturidade dos tecidos.

\section{Composição do óleo essencial das folhas e inflorescências \\ Os estádios de desenvolvimento também afetaram a composição dos constituintes presentes}


no óleo essencial das folhas de $L$. dentata, sendo os teores dos constituintes linalol $(4,7 \% ; 3,1 \%$ e $3,9 \%)$ e $\alpha$-fenchol $(14,3 \% ; 8,3 \%$ e $9,4 \%)$ superiores e de, $\beta$ pineno $(0,3 \% ; 1,9$ e $0,8 \%)$ e limoneno $(0,5 \% ; 2,4 \%$ e $1,0 \%$ inferiores em folhas com as inflorescências em estádios de botão, pré-antese/antese e senescente, respectivamente, comparados aos teores de inflorescências em todos os estádios de desenvolvimento (Tabela 4). O teor de linalol (4,7\%) nas folhas foi superior quando obtido em folhas de ramos com inflorescências em estádio de botão. Porém, os teores de fenchona (11,0\%), $\alpha$-fenchol $(5,6 \%)$ e cânfora $(15,1 \%)$, que foram inferiores em inflorescências em estádio de botão, apresentaram teores superiores em folhas de ramos com inflorescências no mesmo estádio $(14,3 ; 14,3$ e $22,8 \%$ ), respectivamente.
Neste estudo, os teores dos constituintes presentes no óleo essencial das folhas nos diferentes estádios de desenvolvimento, 1,8-cineol $(17,9 \%$ à $22,1 \%)$, cânfora (17,2\% à $22,8 \%)$, fenchona $(12,1 \%$ à $14,3 \%), \alpha$-fenchol $(8,3 \%$ à $14,3 \%), \alpha$-pineno $(0,1 \%$ à $0,9 \%$ ) e $\beta$-pineno $(0,3 \%$ à $1,9 \%)$ diferem dos relatados por Bousmaha et al., (2005), onde a variação dos teores de 1,8 -cineol $(0,9 \%$ à $5,0 \%)$, cânfora $(0,4 \%$ à $0,8 \%$ ) e fenchona $(0,3 \%$ à $0,9 \%)$ presentes no óleo essencial das folhas e ramos foram inferiores em todos os estádios de desenvolvimento, por outro lado, a variação dos teores de $\alpha$-pineno $(4,2 \%$ à $7,7 \%)$ e $\beta$ pineno (14,4\% à $26,0 \%)$, foram superiores. Apenas o constituinte linalol presente no óleo essencial das folhas em estádio de botão (4,7\%) se aproxima do encontrado por Bousmaha et al. (2005), no óleo essencial das folhas no início do florescimento $(6,9 \%)$

TABELA 4. Constituintes (\%) do óleo essencial das folhas e inflorescências de L. dentata em estádios de desenvolvimento floral, 2008.

\begin{tabular}{lccc|ccc}
\hline & \multicolumn{5}{c}{ Local de Armazenamento } \\
\cline { 2 - 6 } Constituintes & \multicolumn{5}{c}{ Folhas } & \multicolumn{3}{c}{ Inflorescências } \\
\cline { 2 - 6 } & \multicolumn{5}{c}{ Estádios de Desenvolvimento } \\
\cline { 2 - 6 } 1,8 Cineol & 17,9 & 22,1 & 18,2 & 23,7 & 21,9 & 27,0 \\
Cânfora & 22,8 & 17,2 & 18,0 & 15,1 & 19,7 & 20,9 \\
Fenchona & 14,3 & 12,5 & 12,1 & 11,0 & 12,3 & 12,9 \\
a-Fenchol & 14,3 & 8,3 & 9,4 & 5,6 & 6,4 & 5,8 \\
Linalol & 4,7 & 3,1 & 3,9 & 3,2 & 2,9 & 1,8 \\
Limoneno & 0,5 & 2,4 & 1,0 & 4,4 & 2,5 & 2,1 \\
$\beta$-Pineno & 0,3 & 1,9 & 0,8 & 5,3 & 2,3 & 2,9 \\
a-Pineno & 0,1 & 0,9 & 0,3 & 2,4 & 0,7 & 1,4 \\
\hline \%Total Identificados & 74,9 & 68,5 & 63,7 & 70,7 & 68,5 & 74,8 \\
Demais Constituintes & 25,1 & 31,5 & 36,3 & 29,4 & 31,5 & 25,2 \\
\hline \% Total & 100,0 & 100,0 & 100,0 & 100,0 & 100,0 & 100,0 \\
\hline
\end{tabular}

e por Kaloustian et al., (2000) durante o florescimento no inverno (5,8\%). No entanto, segundo Kaloustian et al. (2000), o óleo essencial das folhas de L. dentata apresentou, também, como constituintes majoritários a cânfora $(27,8 \%)$ e 1,8-cineol $(1,1 \%)$, mas neste trabalho os teores destes constituintes foi inferior para a cânfora (15,1\% à 22,8\%) e superior para o 1,8-cineol (17,9\% à 27,0\%). O óleo essencial de folhas de L. X intermedia também apresentou variações nos teores dos constituintes durante os estádios de desenvolvimento do tecido foliar (Boeckelmann, 2008), onde o teor de cânfora aumentou com a idade do tecido $(16,6 \%$ no tecido jovem e $56,6 \%$ no tecido adulto) e, portanto, de forma contrária com os resultados obtidos neste trabalho, o teor deste constituinte no óleo essencial das folhas reduziu com o desenvolvimento das inflorescências $(22,8 \%$ no estádio de botão e 18,0\% no estádio senescente).

Resultados contrários também foram relatados por Bousmaha et al. (2005), para os óleos essenciais das inflorescências e da parte aérea sem flores de $L$. dentata, sendo os teores de 1,8-cineol $(21,5 \%), \alpha$-pineno $(2,1 \%), \beta$-pineno $(6,0 \%)$, limoneno $(2,5 \%)$ e linalol $(1,5 \%)$ inferiores em flores e superiores na parte aérea sem flores (1,8-cineol 36,3\%; $\alpha$-pineno $2,9 \%$; $\beta$-pineno $8,1 \%$; limoneno 3,9\% e linalol 1,8\%) e o teor de cânfora $(0,2 \%)$ foi identificado apenas no óleo essencial da parte aérea sem flores. Em lavandin 
(L. angustifolia $\times$ L. latifolia), no mesmo período de colheita, os teores de 1,8-cineol e cânfora foram $55,3 \%$ e $62,5 \%$ respectivamente superiores nas folhas, porém os teores de linalol e acetato de linalila foram superiores $92,5 \%$ e $100,0 \%$ nas flores (Kaloustian et al., 2000). As diferenças dos resultados obtidos neste trabalho podem estar relacionadas ao material genético utilizado, bem como as condições ambientais as quais os experimentos foram conduzidos. Considerando que os constituintes 1,8cineol e cânfora conferem ao óleo essencial de $L$. dentata propriedades medicinais devido à ação antifúngica e bactericida, respectivamente, as folhas também podem ser utilizadas para a produtividade de óleo essencial desta espécie tendo em vista que os teores foram semelhantes aos observados nas inflorescências.

\section{CONCLUSÃO}

O teor e a composição fitoquímica do óleo essencial das inflorescências de $L$. dentata estão associados aos estádios de desenvolvimento floral da espécie e época de colheita.

O maior acúmulo de óleo essencial ocorreu nas inflorescências em estádio de botão em ambas as épocas de colheita, bem como nas folhas no mesmo estádio de desenvolvimento.

\section{AGRADECIMENTO}

À Coordenação de Aperfeiçoamento de Pessoal de Nível Superior (CAPES), pela bolsa concedida.

\section{REFERÊNCIA}

ABURJAI, T.; HUDIAB, M.; CAVRINI, V. Chemical composition of the essential oil from different aerial parts of lavender (Lavandula coronopofolia Poiert) (Lamiaceae) grown in Jordan. Journal of Essential Oil Research, v.17, p.49-51, 2005.

ADAMS, R.P. Identification of essential oils components by gas chromatography/ quadrupole mass spectroscopy. Illinois (USA): Allured Publishing Corporation, Carol Stream, 2001. 452p.

BEUS, C. Growing and Marketing Lavender. Washington State University Extension, v.eb2005, p.1-28, 2006. Disponível em: <http://www.pubs.wsu.edu>. Acesso em: 03 mar. 2008.

BOECKELMANN, A. Monoterpene production and regulation in Lavenders (Lavandula angustifolia and Lavandula x intermedia). 2008. 96p. Dissertação (Mestrado em Ciências) - The College of Graduate Studies, University of British Columbia, Okanagan.

BOUSMAHA, L. et al. Advances in the chemical composition of Lavandula dentata $L$. essential oil from Algeria. Journal of Essential Oil Research, v.17, p.292-

\section{5, 2005.}

BOMBARDA, I. et al. Comparative chemometric analyses of geographic origins and compositions of lavandin var. Grosso essential oils by mid infrared spectroscopy and gas chromatography. Analytica Chimica Acta, v.613, p.31-9, 2008.

CASSELLA, S.; CASSELLA, J.P.; SMITH, I. Synergistic antifungal activity of tea tree (Melaleuca Alternifolia) and lavender (Lavandula angustifolia) essential oils against dermatophyte infection. The International Journal of Aromatherapy, v.12, n.1, p.2-15, 2002.

CHÁVEZ, M.G.C. Hidrodestilacion de aceites essenciales: Modelado y caracterizacion. 2007. 304p. Tese (Doutorado em Engenharia Química) Departamento de Engenharia Química e Tecnologia do Meio Ambiente, Universidade de Valladolid, Valladolid. CHU, C.J.; KEMPER, J.K. Lavender (Lavandula spp.). Longwood Herbal Task Force, p.1-32, 2001. Disponível em: <http://www.longwoodherbal.org/lavender/lavender. pdf $>$. Acesso em: 30 out. 2006.

DA PORTO, C.; DECORTI, D.; KIKIC, I. Flavour compounds of Lavandula angustifolia L. to use in food manufacturing: Comparison of tree different extraction methods. Food Chemistry, v.112, p.1072-8, 2009.

DESCHAMPS, C. et al. Developmental regulation of phenylpropanoid biosynthesis in leaves and glandular trichomes of basil (Ocimum basilicum L.). International Journal of Plant Sciences, v.167, n.3, p.447-54, 2006. DOB, T. et al. Chemical composition of the essential oil of Lavandula dentata L. from Algeria. The International Journal of Aromatherapy, v.15, p.110-4, 2005.

DUDAREVA, N. et al. Developmental regulations of methyl benzoate biosynthesis and emission in snapdragon flowers. The Plant Cell, v.12, p.949-61, 2000. GERSHENZON, J.; Mc CONKEY, M.E.; CROTEAU, R.B. Regulation of monoterpene accumulation in leaves of peppermint. Plant Physiology, v.122, p.205-13, 2000. GOBBO-NETO, L.; LOPES, N.P. Plantas medicinais: Fatores de influência no conteúdo de metabólitos secundários. Química Nova, v.30, n.2, p.374-81, 2007. HAJHASHEMI, V.; GHANNADI, A.; SHARIF, B. Antiinflammatory and analgesic properties of the leaf extracts and essential oil of Lavandula angustifolia Mill. Journal of Ethnopharmacology, v.89, p.69-71, 2003.

KALOUSTIAN, J.; PAULI, A.M.; PASTOR, J. Evolution of camphor and others components in the essential oils of two labiate species during the biological cycle. Analusis, v.28, p.308-15, 2000.

MOON, T.; WILKINSON, J.M.; CAVANAGH, H.M.A. Antibacterial activity of essential oils, hydrosols and plant extracts from Australian grown Lavandula spp. The International Journal of Aromatherapy, v.16, p.9-14, 2006. MUÑOZ-BERTOMEU, J.; ARRILLAGA, I.; SEGURA, J. Essential oil variation within and among natural populations of Lavandula latifolia and its relation to their ecological areas. Biochemical Systematics and Ecology, v.35, p.479-88, 2007.

SANGWAN, N.S.; FAROOQI, A.H.A.; SANGWAN, R.S. Regulation of essential oil production in plants. Plant Growth Regulation, v.34, p.3-21, 2001.

SILVA, E.T. et al. Comportamento da temperatura do ar sob condições de cultivo em ambiente protegido. Revista Acadêmica: ciências agrárias e ambientais, 
v.1, n.1, p.51-4, 2003.

SILVA, F.A.S.; AZEVEDO, C.A.V. A new version of the assistat-statistical assistance software. In: WORLD CONGRESS ON COMPUTERS IN AGRICULTURE, 4., 2006, Orlando, FL, USA. Anais... Orlando: American Society of Agricultural Engineers, 2006. p.393-6.

SIMEPAR - Instituto Tecnológico SIMEPAR. Médias mensais de temperaturas máximas e mínimas, precipitação, da área experimental. Curitiba, PR, 3 nov. 2008.

SOCIEDADE BRASILEIRA DE CIÊNCIA DO SOLO. Comissão de Química e Fertilidade do solo. Manual de Adubação e calagem para os Estados do Rio Grande do Sul e Santa Catarina. Porto Alegre: Sociedade Brasileira de Ciência do Solo, 2004. 400p.

SUDRIÁ, C. et al. Influence of plant growth regulators on the growth and essential oil content of cultured Lavandula dentata plantlets. Plant Cell, Tissue and Organ Culture v.58, p.177-84, 1999.

YUSUFOGLU, A.; ÇELIK, H.; KIRBASLAR, G.F. Utilization of Lavandula angustifolia Miller extracts as natural repellents, pharmaceutical and industrial auxiliaries. Journal of the Serbian Chemical Society, v.69, n.1, p.1 7, 2004.

WERKER, E. Trichome diversity and development. Advances in Botanical Research, v.31, p.1-35, 2000. 